\title{
Féeries
}

Études sur le conte merveilleuX, XVII $-\mathrm{XIX}{ }^{\mathrm{e}}$ siècle

\section{Jean-Paul Sermain, Le Conte de fées du classicisme} aux Lumières

Paris, Desjonquères, 2005. 286 p.

\section{Jean Mainil}

\section{OpenEdition}

\section{Journals}

\section{Édition électronique}

URL : https://journals.openedition.org/feeries/174

DOI : $10.4000 /$ feeries. 174

ISSN : $1957-7753$

\section{Éditeur}

UGA Éditions/Université Grenoble Alpes

\section{Édition imprimée}

Date de publication : 1 février 2006

Pagination : 378-382

ISBN : 2-84310-082-8

ISSN : 1766-2842

\section{Référence électronique}

Jean Mainil, « Jean-Paul Sermain, Le Conte de fées du classicisme aux Lumières », Féeries [En ligne],

3| 2006, mis en ligne le 07 février 2007, consulté le 21 septembre 2021. URL : http://

journals.openedition.org/feeries/174; DOI : https://doi.org/10.4000/feeries.174

Ce document a été généré automatiquement le 21 septembre 2021.

(c) Féeries 


\section{Jean-Paul Sermain, Le Conte de fées du classicisme aux Lumières}

Paris, Desjonquères, 2005. 286 p. $^{1}$

Jean Mainil

1 Le Conte de fées du classicisme aux Lumières constitue une suite à Métafictions (1670-1730). La réflexivité dans la littérature d'imagination (H. Champion, 2002) dont la dernière partie traitait du conte de fées et des récits-cadres ou romans-cadres dans lesquels ils sont enchâssés. Jean-Paul Sermain analysait les contes comme exemples privilégiés de l'univers métafictionnel de l'Âge Classique dans la mesure où «[l] e conte de fées correspond exactement à l'idée de 'métafiction'puisqu'il prend pour objet une fiction et se constitue comme réflexion à son égard " (358). J.-P. Sermain y montre avec brio comment le conte de fées contribue à «l'ambiguïté de l'illusion comme de sa dénonciation » (49) et comment « l'écriture des contes de fées se développe comme une réflexion sur sa propre fiction » (433).

Dans Le Conte de fées du classicisme aux Lumières, la concentration de l'analyse sur le conte de fées permet à J.P. Sermain de retracer l'évolution du genre dès ses débuts jusqu'aux années 1760 . Son but annoncé est ici de «reconstituer la raison poétique, historique et anthropologique du genre et, grâce à cette clef, comprendre les textes voisins pouvant participer de ce mouvement et même y contribuer " (10), textes tels que Grisélidis de Perrault, Marmoisan de Lhéritier ou encore les récits de Boufflers.

Plutôt que de souligner, comme on l'a souvent fait, ce qui sépare les contes d'époques successives, J.-P. Sermain en montre la profonde unité. Le résultat de cette analyse d'un corpus produit sur plus de soixante-dix ans et dans des genres que nous tenons pour séparés (conte, nouvelle, roman) est la réussite du pari annoncé en introduction: "saisir l'unité profonde de ce que la critique a séparé, Perrault, les conteuses classiques, le conte oriental, les récits merveilleux contemporains, dégager ce qui les lie au conte libertin, mais aussi au conte moral et au récit fantastique » (10).

4 Il avait fallu attendre la fin du vingtième siècle pour que R. Robert examine l'ensemble des contes de fées écrits aux XVII ${ }^{\mathrm{e}}$ et XVIII ${ }^{\mathrm{e}}$ siècles dans sa thèse publiée en 1981 qui sera reprise qui sera reprise chez Champion. Après cette contribution de R. Robert, il était 
devenu évident que ce que beaucoup connaissaient du conte de fées de l'Âge classique n'était au mieux qu'un bout de l'iceberg. En 2005, J.-P. Sermain révèle d'autres pans de cet inquiétant iceberg, mais surtout, il relie ce corpus que nos disciplines et nos histoires littéraires ont séparé pour en montrer l'unité profonde, et donc les subtiles variations que subit le conte de fées de 1690 à 1760 .

5 La grande érudition de l'auteur est ici mise au service d'une analyse remarquable à la fois pour son exactitude, sa finesse et son amplitude: qui a travaillé sur le conte connaît bien la difficulté qui consiste à couper à un endroit subjectif mais nécessaire le fil de l'inspiration sous peine de ne jamais arrêter l'analyse. Dans Le Conte de fées $d u$ classicisme aux Lumières, J.-P. Sermain réussit l'autre gageure de nous donner une analyse qui traite du conte de l'Âge classique (peut-être devrait-on, pour suivre Métafiction, parler de méta-fiction merveilleuse ?) dans sa continuité sans perdre le lecteur dans les dédales d'une production littéraire qui travaillait précisément sur la proximité, sur le connu, sur un horizon d'attente prévisible qui rend le conte plaisant pour le lecteur, et parfois ardu pour le chercheur.

6 J.-P. Sermain détaille les trois vagues de la véritable révolution littéraire que constitue le conte de fées, tout d'abord, son «Entrée en fanfare " avec L'Île de la Félicité de MarieCatherine d'Aulnoy (1690), les contes de C. Bernard, Lhéritier, Murat et Perrault. Il montre combien conteurs et conteuses ont contribué à l'essor des Modernes à une époque qui va de la Révocation de l'Édit de Nantes (1685) à la mort de Louis XIV (1715), époque qui « échappe à la caractérisation » et dont on a retenu peu d'œuvres saillantes. J.-P. Sermain montre notamment combien des femmes auteurs qui « écrivent toutes en marge de la littérature savante ou de la grande poésie » et qui " on déjà joué un rôle majeur dans la formation et l'essor du roman français au XVII ${ }^{\mathrm{e}}$ siècle (en dehors du genre comique)» (31) ont contribué à la transformation de la notion d'invention qui «passait par l'appropriation d'une tradition» mais qui est désormais «quête du nouveau » (31).

7 J.-P. Sermain analyse ensuite la seconde période de production merveilleuse qu'il appelle son « Élargissement oriental : 1705-1730 » : Les Mille et Une Nuits d'A. Galland, les Mille et Un Jours de Pétis de la Croix, ou encore les contes de Bignon. J.-P. Sermain analyse également comment entre 1730 et 1756, le conte connaitra encore un franc succès et se diversifiera sous la plume de Hamilton, de Crébillon, mais aussi de La Morlière, Voisenon, Bibiena, Fougeret de Monbron, Cazotte et bien d'autres auteurs moins connus.

8 À la fin du Grand Siècle, et notamment sous la plume de Perrault et de Lhéritier, si le conte « conserve les principales valeurs de la génération classique, en particulier son rationalisme, son esprit critique, son idéal stylistique de simplicité, son intégration de la littérature dans la société, il leur donne une inflexion propre qui peut passer pour un détournement» (11). Or, si le premier xvIII ${ }^{\mathrm{e}}$ siècle poursuit ce mouvement de « contestation indirecte ", à partir des années 1760 a lieu un rejet du merveilleux qui, selon J.-P. Sermain, " accompagne un projet de participation sensible, d'identification de "vérité", qui domine la littérature d'imagination dans la deuxième moitié du XVIII siècle» (11) et dont témoigne par exemple la récriture de La Belle et la Bête de G. de Villeneuve (1740) par Leprince de Beaumont en 1756. Des entreprises éditoriales peuvent alors dresser l'inventaire des contes repris en cabinets tandis que le conte se transforme en deux types de récit qui en sont les héritiers mais s'adaptent aux nouveaux goûts esthétiques, le conte moral et le récit fantastique (29). 
9 Les frontières entre ces trois périodes, bien entendu, ne sont ni absolues ni imperméables et J.-P. Sermain montre bien comment la troisième période, période de « Diversifications (1730-1756) » et ultime période de production merveilleuse, contient trois courants - le conte de fées libertin, moralisant et fantastique - qui «se chevauchent en partie et possèdent deux traits communs ", leur conscience d'occuper une position seconde et le rôle central joué par la morale (28-29).

Les mérites de cet ouvrage ne se limitent pas au fait qu'il ne traite pas un tel conte, ou un tel type de conte, comme la version "dégénérée » ou "édulcorée ", comme «l'ancêtre » ou « la version folklorique » ou encore «mondaine » d'un tel autre conte. L'analyse de tout le corpus permet à J.-P. Sermain de rendre compte de l'évolution du genre à travers l'Âge classique. Il en montre clairement les développements en aval comme en amont.

11 Cet ouvrage a encore le mérite de situer la naissance du conte dans un contexte culturel, littéraire et idéologique qui fut le sien. Au vaste corpus analysé ici, il faut encore ajouter un autre corpus qui est relié au conte et permet de mieux rendre compte de la signification historique, littéraire, culturelle et idéologique du conte de fées comme mode et véritable phénomène de société. Selon J.-P. Sermain, « pour Perrault, le conte implique une transformation du statut et du rôle de la littérature qui donne voix à ce qui jusqu'alors était privé de langue. Ce changement est solidaire d'un autre, qui concerne la conscience du temps et de l'histoire. De façon paradoxale, le conte qui se veut fidèle à un passé reculé, primitif presque, vise à susciter chez le lecteur la conscience tout à fait inédite de la modernité, c'est-à-dire d'un présent sans amarres, fier et inquiet de son autonomie » (37).

Or, comme le montre J.-P. Sermain, cette «modernité » ne peut se comprendre en dehors du cadre de savants " démonologues » qui se développent à partir de la seconde moitié du xve siècle mais connaissent une transformation dans le dernier tiers du Grand Siècle. Ainsi, en 1671 et l'année suivante, des chasses aux sorcières sont interrompues par des arrêts du Conseil des dépêches. À la fin du siècle, philosophes et moralistes se penchent sur l'épineuse question des pouvoirs de l'imagination, Malebranche en 1674-1675 dans De la recherche de la vérité, en 1682 Bayle avec ses Pensées diverses sur la comète et quatre ans plus tard, Fontenelle avec son Histoire des oracles. Selon J.-P. Sermain, le conte qui se développe quelques années plus tard représente son origine et sa transmission sur « la scène originaire de la superstition telle qu'elle a été reconstruite par Malebranche, Bayle et Fontenelle" et elle utilise "les mêmes mécanismes rhétoriques et poétiques qui auraient favorisé les illusions des sorciers et de leurs victimes » (51). Mais on connaît aussi la distance ironique qui sépare les contes d'une "parole populaire» et c'est en cela que les contes constituent un corpus métafictionnel par excellence : le conte, en effet, « repose sur une combinaison instable entre l'adhésion aux 'contes de vieilles', à leur bagage de prodiges et de sortilèges, et un détachement hostile à leurs potentialités superstitieuses, entre une valorisation de l'imagination et de la confiance populaires dans la magie et l'accent mis sur l'absurdité de ces espoirs et croyances » (55).

13 Voilà donc un ouvrage incontournable pour étudiants et chercheurs qui s'intéressent à la poétique de l'Âge classique et au conte de fées dont l'évolution est ici retracée à travers deux siècles et dans son contexte historique, littéraire et culturel. Cet ouvrage sera également indispensable pour qui s'intéresse à la Querelle des Anciens et des 
Modernes, à l'histoire de la fiction en général, ainsi qu'à la contribution de femmes auteurs à la fiction de l'Ancien Régime, ainsi qu'à ses métafictions.

\section{NOTES}

1. Nous avons suivi l'usage prôné notamment par J.-P. Sermain qui refuse la marque féminine des noms d'auteurs et ne dirons pas plus Mademoiselle Lhéritier que l'on ne dit Monsieur Rousseau ou encore Monsieur Perrault. 